\title{
Los límites de la política imperial: el oidor Juan de Barrio Sepúlveda y la frontera esmeraldeña a inicios del siglo XVII
}

Les limites de la politique impériale: l'oidor Juan de Barrio Sepúlveda et la frontière de la région d'Esmeraldas au début du XVII siècle The limits of the imperial politics: the oidor Juan de Barrio Sepúlveda and the border of Esmeraldas area at the beginning of the XVII ${ }^{\text {th }}$ century

\section{Raúl Hernández Asensio}

\section{OpenEdition}

Edición electrónica

URL: http://journals.openedition.org/bifea/3179

DOI: $10.4000 /$ bifea.3179

ISSN: 2076-5827

Editor

Institut Français d'Études Andines

Edición impresa

Fecha de publicación: 1 agosto 2008

Paginación: 329-350

ISSN: 0303-7495

Referencia electrónica

Raúl Hernández Asensio, «Los límites de la política imperial: el oidor Juan de Barrio Sepúlveda y la frontera esmeraldeña a inicios del siglo XVII », Bulletin de I'Institut français d'études andines [En línea], 37 (2) | 2008, Publicado el 01 febrero 2009, consultado el 28 noviembre 2020. URL : http:// journals.openedition.org/bifea/3179; DOI : https://doi.org/10.4000/bifea.3179

\section{(2) $(0 \Theta \Theta$}

Les contenus du Bulletin de l'Institut français d'études andines sont mis à disposition selon les termes de la licence Creative Commons Attribution - Pas d'Utilisation Commerciale - Pas de Modification 4.0 International. 


\title{
Los límites de la política imperial: el oidor Juan de Barrio Sepúlveda y la frontera esmeraldeña a inicios del siglo XVII
}

\author{
Raúl Hernández Asensio*
}

\begin{abstract}
Resumen
Este artículo analiza la política desarrollada por el oidor Juan del Barrio Sepúlveda en la región de Esmeraldas, situada al noroeste de Quito, a comienzos del siglo XVII. A través de este caso se analizan las posibilidades y limitaciones del poder imperial español en las áreas marginales de la América colonial. La política de Sepúlveda descansa sobre un conjunto de alianzas inestables con agentes de poder locales, indígenas y mulatos. Estas alianzas están cimentadas a partir del reparto de bienes y la entrega de regalos por parte de la Real Audiencia. Sin embargo, su operatividad sobre el terreno es limitada. Los cambios de coyuntura muestran la fragilidad de los pactos establecidos y ponen en cuestión su continuidad. Cada una de las partes involucradas maneja agendas propias, que a mediano plazo resultan incompatibles.
\end{abstract}

Palabras clave: frontera, Quito, siglo XVIII, relaciones interétnicas

\section{Les limites de la politique impériale : I'oidor Juan de Barrio Sepúlveda et la frontière de la région d'Esmeraldas au début du XVII ${ }^{\mathrm{e}}$ siècle}

\section{Résumé}

Cet article analyse la politique de l'auditeur royal Juan del Barrio Sepúlveda dans la région d'Esmeraldas, au nord-ouest de Quito, entre 1600 et 1610. Cette étude de cas montre l'étendue et les limites du pouvoir impérial espagnol sur les marges de l'Amérique coloniale. La politique de Sepúlveda repose sur un ensemble d'alliances fragiles avec les détenteurs locaux de pouvoir, indigènes et mulâtres. Ces alliances sont scélées grâce à la distribution de biens et de cadeaux par l'audience royale. Mais, de fait son contrôle est limité. Les changements de conjoncture montrent la fragilité des actes établis et 
remettent en question leurs continuité. Chacune des parties concernées joue son prope jeu, ce qui conduit à moyen terme à les rendre incompatibles.

Mots clés : frontières, Quito, siècle XVIII', rapports interethniques

\title{
The limits of the imperial politics: the oidor Juan de Barrio Sepúlveda and the border of Esmeraldas area at the beginning of the XVII ${ }^{\text {th }}$ century
}

\begin{abstract}
This essay analyses the policy carried out by the oidor Juan del Barrio Sepúlveda in Esmeraldas, a region located to the northeast of Quito, at the beginning of the XVII ${ }^{\text {th }}$ century. This case allows an analysis of the possibilities and limitations of the Spanish imperial power in the marginal areas of the American colonies. Sepúlveda's policy rests on a group of unstable alliances with local authorities, indigenous and maroons caciques. These alliances relied on the distribution of gifts by the Real Audiencia. Nevertheless this policy had a limited success. The changes of conjuncture show the fragility of the established agreements and put in question his continuity. Each of the involved parts handles proper agendas, which medium-term turn out to be incompatible.
\end{abstract}

Key words: frontier, Quito, XVIIth century, interethnic relations

En el mes de octubre de 1568 una compañía de cuarenta soldados parte de Guayaquil con dirección al norte. Su objetivo es una semidesconocida región de la selva costeña situada al norte de la ciudad, donde las fuentes indígenas y los testimonios de los primeros cronistas señalan la existencia de ricas minas de esmeraldas y otras piedras preciosas. Al frente de la partida se encuentra el capitán Andrés Contero, quien había sido comisionado por el gobernador Lope García de Castro para pacificar la región. A Contero, le acompaña su yerno, Bartolomé Martín de Carranza, a quien debemos la narración de la primera parte de esta historia (Martín de Carranza, 1995 [1569]). Tras diversas escaramuzas con la población local, Contero y Carranza fundan en el mes de diciembre la ciudad de Castro, a orillas del «río grande que baja de los Sichos». Pero la historia de Castro es efímera. El acoso continuado de las poblaciones nativas y la hostilidad de los vecinos de Quito, temerosos de perder su derecho preferencial sobre la región, determina que apenas unos meses después, primero Contero y después Carranza deban regresar a Guayaquil, derrotados y sin haber logrado encontrar ninguna de las anheladas minas. Durante los años siguientes tanto Carranza como Contero insistirán en la empresa, hasta encontrar finalmente la muerte en medio de la selva1.

La historia de Andrés Contero es representativa de la suerte corrida por la mayoría de los esfuerzos de colonización del noroeste ecuatoriano. La costa de Esmeraldas continúa siendo hasta el siglo XVIII un territorio de frontera. Este artículo plantea un acercamiento a esta realidad fronteriza a partir del estudio de un capítulo concreto de la historia regional

1 Testimonios al respecto en Expediente del capitán Pedro de Arévalo, vecino de Quito. Quito, 14 de septiembre de 1600 (AGl, Audiencia de Quito: leg. 25). 
esmeraldeña: el proyecto de pacificación y control indirecto desarrollado a comienzos del siglo XVII por el oidor Juan de Barrio de Sepúlveda. Dentro del contexto regional, éste es un episodio excepcional por varios motivos. A diferencia de lo que había sido habitual hasta ese momento, el proyecto de Sepúlveda apuesta por controlar de manera indirecta el territorio, acudiendo a la ayuda de agentes locales, indígenas, criollos y mulatos. Esto supone un cambio de énfasis en la política seguida hasta entonces por las autoridades coloniales. La explicación de este giro hay que buscarla tanto en los propios intereses particulares de su promotor, el oidor Sepúlveda, como en un contexto más general de redefinición de la política imperial en las fronteras americanas, que privilegia el control de los espacios centrales andinos, desincentivando la expansión hacia las regiones de tierras bajas.

El repliegue hacia las tierra altas, evidente a finales del siglo XVI, no responde a una decisión política explícita. David Weber ha señalado que nunca existió una visión política de conjunto respecto a las fronteras imperiales (Weber, 1990). La política de fronteras es siempre una política reactiva, en respuesta a los desafíos establecidos por las poblaciones nativas y por las potencias europeas enemigas de España. En todo momento existen corrientes de opinión diferentes dentro de la administración imperial. Pero, pese a esta ausencia de políticas explícitas, en una perspectiva comparada es posible establecer la existencia de «momentos» diferentes en cuanto a la actitud de las autoridades respecto a los espacios fronterizos americanos. Momentos marcados por sensibilidades, discursos y prioridades que van evolucionando, aunque esta evolución no sea lineal ni progresiva. Entre 1580 y 1620 se asiste a uno de estos momentos claramente definidos: un repliegue generalizado desde las fronteras selváticas hacia los contrafuertes andinos. Un repliegue que coincide con la cristalización de un discurso particular sobre el territorio americano, que proyecta sobre las tierras bajas una imagen de insalubridad, peligro y pobreza. Un territorio inútil para los intereses de la Corona, habitado por unas poblaciones pobres, desorganizadas, hostiles e imposibles de reducir, cuando no directamente perdidas por la causa de la cristiandad.

Es en este contexto de nuevos discursos, de sensibilidades y de políticas en transición, donde se inserta el proyecto de pacificación diseñado por Sepúlveda para la frontera esmeraldeña. La documentación generada en el proceso, relativamente amplia, constituye una oportunidad para observar el funcionamiento en la frontera esmeraldeña de las redes de poder y dominación que sustentan el sistema colonial. El fracaso de Sepúlveda en su proyecto de pacificación remite al carácter conflictivo y multiforme de las relaciones interétnicas establecidas en los espacios fronterizos americanos, la falta de cohesión interna de cada uno de los bloques culturales involucrados en el contacto y las consiguientes dificultades de la administración colonial para plasmar su vocación imperialista en estos territorios ultraperiféricos, alejados de los centros de poder metropolitanos y coloniales. En estos espacios de frontera, los proyectos individuales, protagonizados por europeos, afroamericanos y poblaciones nativas, con frecuencia encuentran espacios desde donde cuestionar, dilatar o incluso anular durante determinados periodos de tiempo, proyectos imperiales diseñados a muchos kilómetros de distancia.

\section{JUAN DEL BARRIO DE SEPÚLVEDA EN QUITO}

Durante la época colonial la gobernación de Esmeraldas era una extensión de territorio de límites mal definidos. Se trata de una región de bosque húmedo tropical, cuyo límite sur confina con la ciudad de Portoviejo. Por el norte se abre hacia la provincia de Las Barbacoas, que administrativamente depende de la gobernación de Popayán. La región se caracteriza por la gran diversidad étnica de sus habitantes. Las zonas más cercanas al 
mar y las cuencas bajas y medias de los ríos que descienden de los Andes, son el hogar de grupos de lengua chibcha-barbacoa, dedicados a la agricultura itinerante del maíz o, con más frecuencia, a la caza, la recolección de productos forestales y la pesca (Palop Martínez, 1994; 1995). Son poblaciones relativamente igualitarias y sin una jerarquía política clara2.

Por lo general, habitan en asentamientos de pequeñas dimensiones, constituidos por grupos familiares más o menos numerosos, casi nunca con más de cincuenta habitantes por aldea. Las laderas occidentales de los Andes, al norte de Quito, y el curso alto de los ríos que descienden hacia el océano Pacífico son el hogar de grupos con una estructura política más compleja, como los litas o los pastos, a medio camino entre los Andes y la selva occidental. Estas poblaciones se asientan en la parte más alta del territorio, por encima de los mil quinientos metros, desde donde proyectan sobre las tierras bajas una zona de influencia que en ocasiones alcanza hasta la costa (Ramón, 1990; Landázuri, 1995; Salomon, 1980). Pero, sin duda, el elemento de mayor originalidad dentro de la frontera esmeraldeña es la presencia continuada de descendientes de antiguos esclavos negros, asentados en pequeñas poblaciones cerca del mar. Su presencia en la región deriva del naufragio de barcos esclavistas que durante la década de 1550 circulan entre Panamá y Lima3. Tras su desembarco en las costas de Esmeraldas, consolidan su posición mediante alianzas con algunas parcialidades indígenas de la región y a través de guerras de conquista emprendidas durante las décadas siguientes ${ }^{4}$. Estos nuevos pobladores de la frontera son denominados en las fuentes españolas «zambos»o «mulatos», lo que probablemente está indicando algún grado de mestizaje con las poblaciones indígenas de la región5. Hacia finales de siglo es posible diferenciar dos asentamientos principales. Uno al norte, en torno a la bahía de San Mateo, y otro más al sur, en las cercanías de la bahía de Atacames. Desde fecha temprana estos emplazamientos fueron conocidos por las autoridades de Quito, que en varias ocasiones trataron de acercarse a ellos para establecer pactos o alianzas que garantizaran la defensa de la región, frente a posibles ataques de otras potencias europeas6. Las comunidades negras de Esmeraldas parecen haber tenido una estructura social relativamente compleja, con jerarquías definidas y clanes prominentes, cuya presencia en la documentación colonial se prolonga a través de varias generaciones

2 Según señala Cabello Balboa en referencia a los campaces, que encuentra cerca de la costa durante su entrada a finales de la década de 1570: «no es gente que reconoce cacique principal, antes es todo confusión, aunque se acaudillan bien contra cualquier enemigo común» (Cabello Balboa, 2001 [1583]: 46).

3 Según señala Alcina Franch, siguiendo a Cabello Balboa, los desembarcos habrían sido dos. El primero hacia 1540-1541, en la bahía de San Mateo, dirigido por Andrés Mangache, y el segundo en 1553 en la región conocida como el Portete, dirigido por Alonso de Illescas (Alcina Franch, 2001: 21).

4 La principal fuente para el estudio temprano de estas comunidades de mulatos es la relación de Miguel Cabello Balboa ya citada. Un estudio completo de ésta y otras fuentes tempranas en los trabajos de Rueda Novoa (1992; 2001; 2005). También Szászdi (1986), Savoia (1988) y Alcina Franch (2001). La revisión de la bibliografía referida a las poblaciones afrodescendientes esmeraldeñas en Hernández Asensio (2006).

5 Ésta era, a comienzos del siglo XVII, la opinión predominante en Quito. En 1600, Pedro de Arévalo señala: «los cuales [mulatos] se mezclaron entre los dichos indios y tomaron sus ritos y ceremonias y traje, y las mujeres que les pareció de las más principales y cacicas y se fueron apoderando y señoreando de aquella tierra e indios de ella». Relación del viaje efectuado por Pedro de Arévalo. Quito, 2 de diciembre de 1600 (AGl, Audiencia de Quito: leg. 25). Un caso similar de mestizaje entre poblaciones indígenas y afrodescendientes es el de los misquitos de la costa atlántica de la actual Nicaragua. Como en Esmeraldas, lo importante es resaltar el carácter colonial de las nuevas poblaciones que surgen a partir del contacto. Una discusión al respecto en Offen (2002).

6 La alianza entre los caciques mulatos y las autoridades coloniales data de la entrada de Cabello Balboa (Rueda Novoa, 2005).

7 La historia de las poblaciones afroamericanas de Esmeraldas tiene aún muchos puntos oscuros. En los últimos años ha emergido una narrativa con cierta carga romántica, que trata de presentarlos como un ejemplo de organización social semiautónoma, con conciencia de sus diferencias étnicas. La autonomía habría cristalizado en la existencia de cacicazgos más o menos consolidados, que agrupaban a los pobladores mulatos del área. Sin embargo, las 
Durante la segunda mitad del siglo XVI, las fuentes recogen constantes referencias a enfrentamientos bélicos entre unos grupos y otros. La guerra intra e interétnica habría sido el elemento característico de la vida social y política de la región aún en tiempos anteriores a la conquista española, asociado probablemente a elementos rituales como la práctica de la antropofagia (Lane, 2002b; Caillavet, 1996). La extensión del sistema colonial, con sus nuevas exigencias en forma de tributos o trabajo personal, habría exacerbado esta tendencia, aumentando el grado de violencia y la acritud de los conflictos al introducir nuevos elementos, como el acceso diferencial a productos como las herramientas de hierro, que pueden suponer para sus poseedores una diferencia sustancial en el contexto de la guerra étnica. Las continuas entradas de conquista en la región, la dislocación de las formas de control social y la extensión de las mitas a las poblaciones serranas, que para evitarlas se internan en la selva, son también elementos que inciden en esta agudización de las tensiones a finales del siglo XVI. El resultado es una situación de guerra generalizada, que las autoridades coloniales deben hacer frente en su empeño de controlar la región.

Hasta la década de 1590 no existe en la frontera esmeraldeña un proyecto colonial definido. La situación cambia con la llegada en 1596 de Juan del Barrio Sepúlveda, quien de inmediato es comisionado para ocuparse de los problemas relativos a la región8. La presencia de Sepúlveda en Quito coincide con un momento delicado en la evolución de la colonia. Tras la revuelta de las alcabalas, la Audiencia de Quito se enfrenta a la doble tarea de recuperar el control político de la situación y adaptar el modelo económico regional a la nueva situación, resultado del descubrimiento de los yacimientos mineros del centro y sur andinos. Se trata de una transición múltiple, que afecta simultáneamente a los planos político, social y económico (Lane, 2002b). Sepúlveda, como funcionario experimentado, se muestra consciente en sus cartas de la magnitud del reto. En 1601 asume como prioridad la necesidad de reforzar el prestigio de la Real Audiencia, dotándola de los instrumentos necesarios para gobernar el territorio y para aumentar su capacidad de recaudación. «Cuando vuestra majestad me mandó venir a servirle de Panamá a esta audiencia», señala:

«teniendo noticia de cuán afligida había estado con las alteraciones pasadas y cuán desautorizada había quedado vuestra real justicia, con menos fuerza que convenía y vuestros oidores afligidos, odiados y poco respetados, procuré por cuantos buenos medios me ha sido posible se restaurase lo perdido». Carta de Juan del Barrio Sepúlveda al rey. Quito, 14 de abril de 1601 (AGI, Quito: 9)

La estrategia desarrollada por Sepúlveda en la frontera esmeraldeña se inserta dentro de estos objetivos generales. Nacido en Antequera, Málaga, pero con amplia experiencia en la Audiencia de Panamá, su actuación puede ser analizada desde distintos puntos de vista9 .

fuentes nos muestran también la existencia de mulatos que no estaban sometidos a estos cacicazgos y que, por el contrario, se mostraban opuestos al liderazgo ejercido por Arobe e Illescas. Es el propio Illescas quien en 1600 advierte a un grupo de españoles que trataban de alcanzar Portoviejo, viajando por la costa en dirección sur «dándonos aviso que nos guardásemos de ciertos mulatos cimarrones que había en aquel camino». Relación de Alonso Sánchez de Cuellar ante la Real Audiencia de Quito. Quito 29 de julio de 1600 (AGl, Audiencia de Quito: leg. 25) —en adelante Relación de Alonso Sánchez de Cuellar-.

8 Ya propuesto en 1594 - Consulta al Consejo de Indias. Lima, 13 de diciembre de 1594 (AGI, Lima: 1)—, Sepúlveda fue nombrado oidor en Quito en marzo de 1595 (Real Provisión concediendo a Juan del Barrio de Sepúlveda, oidor de Panamá, el título de oidor de Quito. Madrid, 22 de marzo de 1595 [AGI, Quito: 211]). Tras diversas vicisitudes su llegada a la ciudad tiene lugar el 31 de octubre de 1596 (Carta del oidor Juan del Barrio Sepúlveda, oidor de la Audiencia de Quito. Quito, 5 de junio de 1597 [AGI, Quito: 8]). Desde el primer momento es encargado de ejercer la política de fronteras, probablemente por la experiencia con que contaba al haber hecho frente en diversas ocasiones a los intentos ingleses de apoderarse de las ciudades del istmo.

9 Tras realizar sus estudios en Salamanca, inicialmente, Sepúlveda había sido nombrado como oidor en la Audiencia de Santo Domingo en 1575. No llegó a ejercer, sin embargo, este cargo, siendo nombrado para Panamá en 1580 
En el plano personal, su nombramiento como oidor en Quito supone para Sepúlveda una profunda decepción ${ }^{10}$. Desde el primer momento, su meta consiste en acumular los méritos necesarios para ser promocionado a un destino mejor, en Lima o en México11. Probablemente por esta razón, sus relaciones con la elite local, nunca son del todo buenas, ni siquiera en lo que se refiere a los demás ministros de la audiencia. Su política esmeraldeña es más un asunto personal que un empeño colectivo. Se trata, ante todo, de servir al Rey y de demostrar su aptitud para empresas mayores. Estas circunstancias marcan las características de la política a desarrollar. Para alcanzar sus aspiraciones de promoción administrativa, Sepúlveda requería de resultados inmediatos, que pudieran ser presentados como prueba de sus méritos a las autoridades metropolitanas. Adicionalmente, por su trayectoria como funcionario imperial, Sepúlveda se muestra profundamente desconfiado respecto a la capacidad de las élites locales quiteñas para asegurar la administración del territorio. Esta consideración negativa incluye tanto a las élites propiamente criollas como a aquellos soldados y aventureros procedentes de España pero que instalados en las colonias desde tiempo, proyectaban sobre el territorio sus expectativas de conquista y enriquecimiento ${ }^{12}$.

Estas dos circunstancias, la necesidad de resultados inmediatos y la desconfianza hacia las élites locales, llevan a Sepúlveda a optar por una política de control indirecto del territorio, basada en cinco ejes:

- El establecimiento de alianzas con los caciques mulatos de las regiones cercanas a la costa.

- La concreción de alianzas similares con los principales caciques de la región del pie de monte del corregimiento de Otavalo.

- La reducción de las poblaciones indígenas de las regiones de las cuencas alta y media de los ríos que descienden de los Andes y su concentración en pueblos de nueva fundación atendidos por sacerdotes mercedarios.

- La fundación de dos poblaciones de españoles en las regiones de la costa, susceptibles de convertirse en puertos para el abastecimiento de Quito y para la salida de textiles.

- La apertura de un camino entre la capital de la Audiencia y las nuevas poblaciones costeras.

La política de Sepúlveda se apoya en la representación dicotómica de las poblaciones nativas de la frontera. Esta representación tenía como eje la división entre indios pacíficos (más o menos asimilables) e indios de guerra (definitivamente no asimilables). En este sentido, Sepúlveda plantea una estrategia de dos caras: asimilar a los primeros para utilizarlos en la contención de los segundos. Dada la escasez de documentos, resulta difícil

(Carta de Juan del Barrio Sepúlveda al rey. Quito, 25 de mayo de 1527 [AGI, Quito: 8]). Su traslado a América tuvo lugar en 1583 (Expediente de concesión de licencia para pasar a Tierra Firme, a favor del doctor, Juan del Barrio Sepúlveda, natural de Antequera, con Gabriel de Trillo, natural de Almonacid, Francisco Martín de Salamanca y Bartolomé Gómez, criados [AGI, Indiferente: 2093]). Desde entonces había ejercido en esta Audiencia como oidor sin ser ascendido ni promocionado, pese a haber realizado funciones eventuales de presidente en casos de vacancia, como oidor más antiguo.

10 En su primera carta escrita en Quito, señala: «(...) me dispuse a venir a servir a Vuestra Majestad como lo hago en esta audiencia en plaza de oidor más nuevo siendo el más antiguo oidor de cuantos oidores Vuestra Majestad tiene hoy día en sus reales audiencias de Santo Domingo, Panamá, Nuevo Reino, Quito, Los Reyes y Charcas y dicen otros que en Nueva España (...)» (Carta de Juan del Barrio Sepúlveda al rey. Quito, 25 de mayo de 1527 [AGI, Quito: 8]).

11 De hecho en 1597, ya aparece dentro de una lista de posible oidores propuestos ante el Consejo de Indias para ejercer en la Audiencia de Lima (Consulta del Consejo de Indias. Lima, 16 de octubre de 1597 [AGI, Lima: 1]).

12 En una carta de abril de 1600, señala respecto a la política de sus predecesores: «(...) salen cada día otros [nativos] de mejor gana y perdido el temor que tenían y habían cobrado a los españoles por las crueldades y malos tratos que siempre de ellos han recibido cuando han entrado a mano armada a los querer pacificar o por mejor decir robar y quitarles sus mujeres e hijos y venderlos como esclavos». Carta de Juan del Barrio Sepúlveda, oidor de Quito, a Su Majestad. Quito, 15 de abril de 1600 (AGI, Quito: 9). 
saber en qué medida este enfoque responde a un plan preconcebido y en qué medida se fue desarrollando conforme las oportunidades se presentaron13. Es evidente, no obstante que la idea no procede directamente del oidor. La presencia de Sepúlveda en Salamanca, durante su periodo de estudios, es poco tiempo posterior al debate establecido entre los partidarios de Bartolomé de las Casas y los partidarios de Juan Ginés de Sepúlveda. Estas coincidencias hacen muy probable que el Sepúlveda quiteño haya estado influido por su tocayo, andaluces ambos, respecto al diseño de su argumentación en lo que se refiere a la justificación de la presencia española en el nuevo mundo. En ambos casos la diferenciación entre indios amigos e indios hostiles es la puerta que abre el camino para legitimar el expansionismo colonial y la imposición de formas de gobierno europeas sobre las poblaciones nativas.

\section{LA COOPTACIÓN DE LOS PODERES INDÍGENAS DE LA FRONTERA COMO ESTRATEGIA DE CONTROL TERRITORIAL}

La política de control indirecto de la frontera desarrollada por Sepúlveda se basa en la cooptación por parte de las autoridades quiteñas de los principales poderes locales de la frontera. Sepúlveda busca en primer lugar el apoyo de los caciques mulatos, quienes desde 1570 se habían estado acercando a las autoridades de Quito, ofreciéndose a controlar la región a cambio del reconocimiento de una cierta autonomía en el manejo de sus asuntos14. Desde 1599, bajo la supervisión de Sepúlveda, algunos caciques mulatos se desplazan hasta Quito, donde son agasajados por las autoridades en reconocimiento de su papel como guardianes de la frontera. Al menos son tres las visitas realizadas, dos por parte del cacique Francisco de Arobe y una por parte de Alonso Sebastián de Illescas. En la capital de la Audiencia, en la iglesia de San Blas, los caciques son bautizados por el obispo de la ciudad con la presencia de las principales autoridades de la región (Relación del viaje efectuado por Pedro de Arévalo. Quito, 2 de diciembre de 1600 [AGI, Quito: 25]). El propio Sepúlveda actúa como padrino. En otros casos este papel corresponde a otros ministros de la audiencia. Las visitas de los caudillos de la frontera a las capitales del poder colonial no son algo excepcional dentro del repertorio de políticas aplicadas en las fronteras indígenas del imperio español. Esta práctica había sido ensayada con relativo éxito en el caso de las poblaciones chichimecas del norte de Nueva España, región en la que al igual que en Esmeradas se había planteado a finales del siglo XVI una estrategia indirecta de pacificación, a partir de la cooptación de los principales poderes locales por parte de la administración colonial (Powell, 1944). Es difícil saber si Sepúlveda conocía la experiencia de Nueva España, anterior en el tiempo a su llegada a Quito, o si se inspiró en ella a la hora de desarrollar su política hacia la región fronteriza. No es imposible que fuera así, ya que se trataba de un funcionario experimentado, que previamente había desarrollado funciones similares en la Audiencia de Panamá.

13 Pese a su experiencia haciendo frente a las invasiones inglesas y holandeses, que probablemente le valieron su traslado a Quito, el propio Sepúlveda señala desde el primer momento el carácter singular de la guerra de fronteras en las tierras bajas occidentales. Todo, según señala, «ha sido muy diferente de las guerras que tuve en Panamá». Carta de Juan del Barrio Sepúlveda, oidor de Quito, a Su Majestad. Quito, 12 de abril de 1599 (AGI, Quito: 9).

14 Ésta es la interpretación defendida por Rueda Novoa en su estudio sobre el tema, antes citado (Rueda Novoa, 1998). Hay que tener en cuenta, en este sentido, que los mulatos de Esmeraldas se encuentran totalmente aislados. No hay a su alrededor ninguna zona esclavista, que les permita aumentar su población con fugas o de otra manera. En esto se diferencian de los palenques del Caribe o de Brasil, e incluso de la propia situación de Esmeraldas en el siglo XVIII, a partir de la apertura de las minas de la región de Barbacoas, situada más al norte. Al respecto ver Lane (2002a). 
En el curso de una visita realizada en 1599, el pintor indígena Andrés Sánchez Gallque plasma por encargo de las autoridades de la Audiencia el retrato del cacique Francisco de Arobe y de sus hijos Pedro y Domingo ${ }^{15}$. Este retrato, muy conocido, es un buen resumen de las actitudes quiteñas hacia los mulatos de la frontera. Los caciques mulatos retratados por Gallque están revestidos de elementos procedentes de la cultura española de la época, como las ropas, los sombreros, etc. Pero sus retratos poseen también rasgos exóticos, como las narigueras, que según algunos autores son una herencia de las tribus de la selva y serían, por lo tanto, un rasgo de una primera aculturación, previa al contacto con los españoles (Saville, 1907; 1910). Estas joyas, aparentemente de oro, recalcan una vez más la riqueza que sobre la zona proyectaban las representaciones geográficas procedentes del primer momento de la Conquista. Orgullosos, erguidos, ricamente ataviados, armados con sendas lanzas con puntas de hierro, los caciques mulatos demuestran su carácter de jefes guerreros, celosos guardianes de la frontera.

Pero la alianza entre la Real Audiencia y los caciques mulatos de la costa tiene también otros elementos, que van más allá de lo meramente simbólico. Las visitas a Quito de los caciques mulatos están acompañadas de la entrega por parte de la Real Audiencia de gran número de regalos a los principales de estos caciques. Entre los productos más frecuentemente demandados se encuentran sobre todo las herramientas de metal y los tejidos16. Estos donativos se repiten también en el caso de los caciques indígenas del norte de la frontera. Las entregas son demasiado frecuentes para tener únicamente un significado simbólico. En diversos documentos aparecen referencias muy explícitas, que permiten intuir la existencia de un circuito comercial, que alimenta las alianzas y al mismo tiempo es alimentado por ellas. Desde esta perspectiva podemos comprender la presencia de personajes como Baltasar de Medina, de quien se nos dice que es vecino de Quito y a quien encontramos residiendo en San Martín de Campaces en 1601, en compañía del padre Juan Bautista de Burgos (Carta de Baltasar de Medina, vecino de Quito, al oidor Juan del Barrio de Sepúlveda. San Martín de Campaces, 30 de diciembre de 1600 [AGl, Quito: 25]). Poco después, Medina aparece firmando en nombre de Illescas y sus hijos, iletrados todos ellos, el asiento establecido con las autoridades de la Real Audiencia17. Por documentos conservados en el Archivo Nacional de Historia de Quito sabemos además que Medina trabajaba por cuenta de la Audiencia recibiendo ciertas sumas de dinero de manera periódica, como contraprestación de sus serviciosi18. Se trata, por lo tanto, de un auténtico mediador cultural, cuyas actuaciones apuntan hacia dos direcciones: en Esmeraldas facilita a las autoridades coloniales la ejecución de su política fronteriza y en Quito actúa como parte del grupo de presión que interviene en favor del reconocimiento

15 El cuadro se conserva en el Museo de América de Madrid. Sobre el mismo pueden verse tres pequeños trabajos: Szászdi (1986), Cummins (1999) y Cummins \& Taylor (1998).

16 Carta de la Audiencia de Quito a Su Majestad. Quito, $1^{\circ}$ de abril de 1599 (AGI, Quito: 9). Cuando ocurrían encuentros inesperados, las herramientas de hierro eran también la primera demanda de los mulatos. Esto ocurre, por ejemplo, en el momento del encuentro entre el capitán Sánchez de Cuellar, y los mulatos del grupo de Illescas: «... al cabo de cuatro días trajo dos canoas cargadas de bastimentos, lo cual repartió entre nosotros con mucho amor y voluntad, dándole nosotros algunos cuchillos, que él pidió, y otras cosillas en recompensa» (Relación de Alonso Sánchez de Cuellar). Las dificultades para obtener productos de hierro se ponen en evidencia en el momento de describir las armas de los mulatos, en la carta que acompaña el cuadro enviado al Rey. Señala Sepúlveda aquí: «... traen de ordinario lancillas en las manos y tres o cuatro dardos de madera recia $y$, aunque sin hierros, muy agudos...». Carta de la Audiencia de Quito a Su Majestad. Quito, $1^{\circ}$ de abril de 1599 (AGI, Quito: 9).

17 Asiento hecho por la Real Audiencia de Quito con Alonso Sebastián de Illescas. Quito, 13 de julio de 1600 (AGI, Quito: 25).

18 Archivo Nacional de Historia (Quito, sección Real Hacienda, caja 36). Libro de Hacienda Real y otros géneros del cargo del contador Francisco de las Cabezas del año de 1599, asiento de egresos correspondiente al día 10 de febrero de 1600 . 
de los caciques mulatos. El sentido último de sus gestiones, por desgracia, se nos escapa al no haberse conservado ningún tipo de documento personal que nos permita insertarlo dentro de la sociedad quiteña de su tiempo.

El acercamiento a los caciques mulatos implica la puesta en marcha de un ambicioso proyecto de reordenamiento de la frontera. En los asientos firmados con ocasión de las visitas realizadas a Quito, los caciques se obligan a concentrarse en dos poblaciones recientemente fundadas, San Mateo de las Esmeraldas y San Martín de Campaces, donde deben construir casas para los doctrineros mercedarios encargados de su evangelización 19 . Se comprometen también a hacer poblar en estos asentamientos a los indígenas bajo su control. San Mateo y San Martín debían servir como puntos de referencia para la fundación de dos pueblos de españoles en puntos estratégicos de la costa. En su regreso hacia la costa, Illescas y sus hijos son acompañados por Pedro de Arévalo, un viejo conquistador comisionado ahora por la Real Audiencia para reconocer el territorio con vistas al futuro trazado de un camino que permita exportar los textiles serranos omitiendo la larga ruta de Guayaquil20.

El primero de estos establecimientos es, en realidad, algo anterior a la presencia de Sepúlveda en Quito. Había sido fundado a mediados de la década de 1590 por Francisco Arias de Herrera, corregidor de Guayaquil, con el objetivo de contar con un puerto de salida para el comercio quiteño (Carta de la Real Audiencia de Quito, a Su Majestad. Quito, 4 de abril de 1596 [AGI, Quito: 8]). Contamos con información muy fragmentaria respecto a sus primeros años de existencia. Algunas referencias permiten, sin embargo, entrever la existencia de diferencias entre el estilo de gobierno desarrollo por Arias de Herrera, que prácticamente buscaba someter a la población local a un régimen de esclavitud, y los caciques mulatos de la región, que una y otra vez optan por desamparar el pueblo, huyendo a sus refugios en el interior de la selva21. Solo en los últimos años del siglo XVI parece haber cambiado esta situación. Hacia 1600 los documentos señalan la existencia de una población más o menos consolidada, en la cual reside de manera estable el cacique Pedro de Arobe, considerado por los españoles el principal de la región (Carta de Juan del Barrio de Sepúlveda, oidor de Quito, a Su Majestad. Quito, 15 de octubre de 1600 [AGI, Quito: 9]).

Al contrario de lo que ocurre con San Mateo, San Martín sí puede ser considerado un fruto directo de la política de Sepúlveda. Su fundación tiene lugar en 1601 como resultado del asiento firmado ese año con Alonso Sebastián de Illescas (Carta de Juan del Barrio de Sepúlveda, oidor de Quito, a Su Majestad. Quito, 14 de abril de 1601 [AGI, Quito: 9]). Los testimonios de la época presentan a los dos emplazamientos como centros de reunión, lugares de intercambio donde confluían en ocasiones especiales los mulatos que habitaban el área y las poblaciones indígenas sometidas a ellos22. Características similares parecen haber tenido los pueblos fundados al norte de la frontera, en torno a la cuenca alta de los ríos occidentales andinos. De acuerdo con un documento de la Real Audiencia, son más

${ }^{19}$ Asiento hecho por la Real Audiencia de Quito con Alonso Sebastián de Illescas. Quito, 13 de julio de 1600 (AGI, Quito: 25). Este documento ha sido trascrito como apéndice en Cabello Balboa (2001).

20 Relación del viaje efectuado por Pedro de Arévalo. Quito, 2 de diciembre de 1600 (AGl, Quito: 25). Este documento, que es el diario de la expedición de Arévalo, ha sido trascrito en González (1949). Un análisis al respecto puede verse en Hernández Asensio (2004).

21 Expediente del capitán Pedro de Arévalo, vecino de Quito. Quito, 14 de septiembre de 1600 (AGI, Quito: 25). Se trata de la probanza de méritos, que recoge sus servicios durante los años anteriores.

22 Carta del padre Joan Bautista de Burgos a Juan del Barrio de Sepúlveda, oidor de Quito. San Martín de Campaces, 30 de diciembre de 1600 (AGl, Quito: 25) y Carta de Baltasar de Medina, vecino de Quito, al oidor Juan del Barrio de Sepúlveda. San Martín de Campaces, 30 de diciembre de 1600 (AGI, Quito: 25). 
de diez los pueblos fundados durante estos años23. Al igual que ocurre en la costa, hay que buscar el origen de estos pueblos en la alianza de la Real Audiencia con los poderes indígenas locales. Durante los últimos años del siglo XVI, en paralelo a las paces firmadas por los caciques mulatos, Sepúlveda establece acuerdos con caciques indígenas de las regiones de la ceja de montaña del corregimiento de Otavalo, hasta llegar a conformar un arco de «gobernaciones» nativas, que abarca desde el sur de Popayán hasta el norte de la ciudad de Quito24. Con la documentación disponible, describir las vicisitudes de cada una de estas alianzas es imposible. El esquema, sin embargo, es similar en todos los casos documentados: el reconocimiento oficial recae en un cacique cristianizado de la región de los contrafuertes andinos, que toma a su cargo el control y pacificación de varias etnias selvícolas situadas en las inmediaciones de su población de residencia. Las intervenciones están acompañadas del establecimiento de doctrinas religiosas en áreas avanzadas de la selva. El objetivo de estas fundaciones no es concentrar la población selvícola, según el modelo jesuita, pues esto era algo que las autoridades coloniales sabían por experiencia que era inútil. Lo que Sepúlveda pretende con estas alianzas es establecer una serie de puestos de avanzada que facilitaran el tránsito por la región, el control de los sistemas fluviales y el acceso a hipotéticos yacimientos de oro y piedras preciosas.

La primera oportunidad de aplicar la política de control indirecto se le presenta a Sepúlveda en 1597, con motivo de la llegada a Quito de los caciques de Lita, don Luis y su hijo don Alonso Gualapiango, acompañados del doctrinero de la región, el padre Gaspar de Torres. Los caciques de Lita habían desarrollado una activa política de expansión desde la década de 1570 (Ramón, 1990). Entre las poblaciones sometidas a su control se encuentran los cayapas, un grupo étnico que en Quito se consideraba relativamente pacífico, pero que aún no había sido cristianizado. Con el aval de la Real Audiencia, Torres y los caciques litas se internan en la región. El objetivo de la entrada era doble: agrupar a la población cayapa en dos o tres doctrinas y establecer un límite frente a los grupos selvícolas hostiles, especialmente los malabas situados entre los ríos Mira y Mataje. En el territorio controlado por los cayapas, que para ese momento ya mantenían algún tipo de relación de dependencia con los caciques litas, se había concentrado poblaciones de diverso origen étnico provenientes del interior de la selva. Subordinado a Luis Gualapiango, el cacique cayapa contaba a su vez con su propio grupo de caciques subordinados. Según evidencia, el diario escrito por el padre Torres —esta incipiente jerarquización de las parcialidades nativas de las tierras bajas - conlleva también su progresiva agrupación en unas pocas poblaciones de mayor tamaño. El origen de estos cambios habría que buscarlo en la hostilidad de los indios malabas, a cuya intervención se atribuye el repliegue de los caciques cayapa hacia los dominios de caciques litas. Ésta es, al menos, la interpretación asumida en los documentos coloniales, aceptada hasta hace poco por la mayor parte de los autores (Palop Martínez, $1994 ; 1995) 25$. Sin negar la pertinencia de la guerra como elemento desestructurador de las sociedades nativas de la frontera esmeraldeña, podemos preguntarnos, sin embargo, por el impacto de la intensificación de los circuitos comerciales resultado de la política de control indirecto desarrollada por Sepúlveda. El posible origen «comercial» de la alianza entre

23 Sumario de lo realizado por el oidor Juan del Barrio de Sepúlveda, sobre lo hecho en la conversión de las Esmeraldas. Quito, 14 de abril de 1600 (AGl, Quito: 25). Este documento ha sido trascrito en Burgos (1995: 377-387).

24 La mayor parte de estas gobernaciones eran meramente nominales. Solo Luis y Alonso Gualapiango en Lita y el cacique García Tulcanaza más al norte parecen haber ejercido, durante cierto tiempo, un control efectivo sobre las parcialidades que les son señaladas bajo su gobierno.

25 Torres se refiere explícitamente a ello en: expediente sobre la conversión de Lita y pueblos circunvecinos, 1597 (AGl, Quito: 9, f. 8v). Este documento incluye el diario de Gaspar de Torres y las cartas referidas a sus entradas. La fecha corresponde al comienzo del expediente, pero los documentos en su mayoría son de los años 1598 y 1599. 
cayapas y litas ha sido apuntado recientemente por Warren De Boer (1994). El diferente grado de acceso a productos de origen europeo, como las herramientas de hierro o los textiles, es otro elemento que influye de manera significativa en la generación de redes de dependencia entre unos grupos y otros. Como ya hemos señalado, son muchos los documentos que presentan a Luis y Alonso Gualapiango actuando como intermediarios en el reparto de productos europeos. La posibilidad de ampliar su control en el acceso a estos productos habría sido la clave del acercamiento de los caciques cayapas. Un testimonio de Hernán González de Saa, apunta también en este sentido, al llamar la atención sobre el proceso de cambio en las formas de vestir de la población indígena, percibido durante sus entradas en el extremo septentrional de la frontera 26.

La exacerbación de la violencia que se observa a finales del siglo XVI, habría tenido como resultado el aumento de la dependencia de unos grupos respecto a otros. Los asentamientos se hacen más cercanos entre sí, al tiempo que aumentan sus dimensiones. Como apunta Galo Ramón a partir del análisis del mapa que acompaña el texto de Torres, se alejan también de las orillas de los ríos, las vías naturales de penetración en el interior de la selva (Ramón, 1990: 126)27. Por contraste, las referencias a la existencia de pequeñas malocas abandonadas son frecuentes en la documentación de la época. Los asentamientos familiares parecen haber sido sustituidos progresivamente por poblados de dimensiones medianas, como el del cacique Cayapa, que albergaba a varios centenares de habitantes, dando lugar a un ordenamiento social más complejo y jerarquizado. Estos asentamientos funcionan también como centros ceremoniales sobre los cuales confluye la vida social de las poblaciones selváticas. La alta proporción de hombres respecto a las mujeres bautizadas por Torres en algunos ayllos, permite suponer que se trata de grupos de no residentes, desplazados hasta las aldeas centrales de su agrupación étnica para participar en estos eventos28. Al menos hasta inicios del siglo XX, ésta es una práctica que se mantiene entre los grupos cayapa, asociada a eventos religiosos que tienen también ingredientes comerciales y refuerzo de la identidad cultural (Barret, 1994)29.

Sea por motivos bélicos o como estrategia para acceder con mayor fluidez a productos comerciales, Cayapa, a su vez, habría consolidado su posición a través de la alianza con los caciques de Lita, Luis y Alonso Gualapiango. Dentro de este cuadro, únicamente los malaba parecen ser la excepción 30 . Torres atribuye a esta parcialidad una actitud hostil frente a sus

26 Señala González de Saa: «... el uso antiguo del vestir de estos naturales es una manera de telilla de cáscara de árboles (...) aunque ahora se van vistiendo de mantas y camisetas de algodón con el comercio que hemos tenido con ellos». Relación de Hernán González de Saa sobre sus viajes a Esmeraldas. Quito, 11 de abril de 1600 (AGI, Quito: 25) —en adelante Relación de Hernán González de Saa-.

27 La predilección por parajes fáciles de defender, alejados de los ríos, se observa también en la descripción que Sánchez de Cuellar hace del emplazamiento original, previo a su relocalización en San Martín de Campaces, de cacique Alonso de Illescas. Señala Cuellar: «... fuimos a su casa que estaba de la mar seis leguas poco más o menos de un río a la entrada del cual la mar hace muchas olas y esteros con que la entrada a la dicha casa se hace muy dificultosa a quien no la ha cursado muchas veces donde llegados vimos una casa pequeña de un indio súbdito del dicho capitán y desembarcado allí subimos por un cerro pequeño a la bajada del cual pasado el río que allí es muy pequeño vimos la casa del dicho capitán que está metida entre cuatro cerros poblada en lo llano de la falda de ellos...» (Relación de Alonso Sánchez de Cuellar).

28 Por ejemplo, en el relato de Saa de sus viajes por la región, señala: «... a este asiento acudió la gente de todos los demás aquí referidos el día de carnestolendas a dónde se holgaron mucho haciendo juegos e invenciones a su usanza y al nuestro de que los ejercitamos de que recibieron mucho contento - y el día de ceniza les predicó el dicho padre por la lengua que los entendía (...) y luego acudieron al dicho padre a pedir que los bautizasen...» (Relación de Hernán González de Saa).

29 Basado en la experiencia del autor durante los años 1908-1909.

30 La situación de los malaba, dentro del marco regional de las tierras bajas durante la época estudiada, es ambigua. Por una parte, se insiste en su carácter belicoso; por otra, Torres transmite datos que apuntan a un cierto nivel de vinculación tanto con los núcleos hispano criollos serranos como con algunos de los caciques gobernadores de pie 
vecinos, quienes los consideraban «indios de guerra», imposibles de reducir31. A finales del siglo XVI, la desestructuración de los modelos tradicionales de residencia, producto de la intensificación de la intervención española en el área norandina, contribuye a desdibujar las fronteras étnicas, generando una situación muy fluida en donde observar procesos complejos de reinvención y negociación de identidades. La política intervencionista de Sepúlveda y un conjunto de afortunadas (para nosotros) circunstancias nos permiten observar con cierto detalle estos procesos. Desde este punto de vista, constituyen una oportunidad excepcional para observar cómo el estado colonial español, interactúa con los actores locales en un espacio periférico, donde los balances de poder, ambiguos y cambiantes, obligan a una constante negociación de las formas de dominación.

\section{INTERESES PARTICULARES Y ALIANZAS COYUNTURALES: LOS LÍMITES DE LA POLÍTICA DE SEPÚLVEDA}

La cooptación de los poderes locales es el elemento central de la estrategia de control indirecto desarrollada por Sepúlveda. En Quito el principal apoyo de esta política son los sacerdotes de la orden de la Merced, que desde el último tercio del siglo XVI recorren la región (Monroy, 1935). Los sacerdotes mercedarios, de acuerdo con los planes de Sepúlveda, debían hacerse cargo de los nuevos poblados fundados en las zonas de frontera. La alianza entre la Real Audiencia, los padres mercedarios y los caciques indígenas tiene un carácter funcional. Los sacerdotes estaban interesados en crear una zona libre de la influencia de otros actores que pudieran amenazar sus intereses en la región, mientras que la Real Audiencia, que debía hacer frente a situaciones similares en las fronteras de la selva oriental, no contaba con los recursos para ejercer una política de control directo de la región. Para los caciques nativos suponían un reconocimiento de la primacía alcanzada en el ámbito local en las décadas previas, y una oportunidad para consolidar su poder mediante la manipulación de los circuitos de distribución de los productos europeos en las tierras bajas. Son estas alianzas coyunturales las que sustentan las «gobernaciones» indígenas, que son la base de la política de Sepúlveda en la mitad norte de la frontera. Las expediciones de reconocimiento realizadas en el interior de la región fronteriza son un ejemplo de esta particular confluencia de intereses.

Durante el periodo estudiado, las poblaciones nativas y sus caciques actúan como auxiliares en varias entradas protagonizadas por agentes de la Real Audiencia. No se trata, en este sentido, de pequeñas partidas, sino de auténticas expediciones que pueden congregar a varios centenares de auxiliares nativos, acompañados de unos pocos soldados españoles. En 1598, para su entrada hasta la costa, Hernán González de Saa cuenta con la colaboración inicial de «cien indios de Lita». Posteriormente, tras una estancia en el poblado de Espíritu Santo de los cayapa, la comitiva asciende a «más de trescientos indios de Lita y del dicho pueblo». Llegados al embarcadero «del río Pumbi», el viaje prosigue en cuarenta y seis balsas, «en las cuales llevamos doscientos nueve indios y los demás los hicimos volver de

de monte andino. Sería interesante estudiar el caso de esta etnia como un proceso de construcción del «otro» a partir de un estereotipo descontextualizado, similar aunque con menor intensidad al operado en fechas similares con la etnia de los jíbaros. Al igual que éstos, los malaba aparecen como una etnia con la única personalidad particular, a partir de un ethos que se considera especialmente violento, dentro de un contexto en el cual el resto de las etnias vecinas carecen de identidad singularizada. El caso de los shuar, o indios jíbaro de la frontera oriental amazónica es, de alguna manera, similar y mucho más conocido. Véase Taylor (1994).

31 Expediente sobre la conversión de Lita y pueblos circunvecinos, 1597 (AGl, Quito: 9, f. 8v). Hasta comienzos del siglo se mantiene entre los cayapa una tradición oral referida a los «indios bravos», sus vecinos y enemigos (Barret, 1994: 34 y ss.) El análisis de esta tradición oral en De Boer (1994). 
los de Lita por no saber bogar» (Relación de Hernán González de Saa: f. 1r-1v). Para la Real Audiencia, el objetivo de estas entradas era múltiple: reconocer el territorio en busca de una ruta adecuada para el futuro camino entre Quito y las nuevas poblaciones de la costa, asentar su soberanía sobre las poblaciones nativas mediante rituales de reconocimiento, controlar a estas poblaciones favoreciendo su agrupamiento en unos pocos asentamientos supervisados por sacerdotes mercedarios, etc. Desde la perspectiva de los caciques indígenas implicados en ellas, la funcionalidad de estas expediciones es más compleja.

Diversos testimonios muestran que ocasionalmente las poblaciones indígenas de las cuencas altas y medias realizan sus propias expediciones a la región costera para obtener productos como la denominada «sal de los indios», un producto saborizante y preservante que extraían a partir de los maderos arrojados por el océano a la playa (Relación de Hernán González de Saa: f. 1v). Estas expediciones podían durar varias semanas y ocupaban a prácticamente toda la población adulta masculina de una determinada parcialidad32. Es probable que las expediciones realizadas en compañía de los delegados de la Real Audiencia se insertaran dentro de este esquema autóctono de control del territorio y gestión de recursos. En este sentido apuntan los complejos procesos de negociación que rodean la preparación y el desarrollo de las entradas. Los caciques nativos tratan de condicionar el alcance de los viajes, las rutas a seguir, la asignación de responsabilidades e incluso el reparto de las provisiones. Esto ocurre durante la entrada antes comentada de Hernán González de Saa. Llegado al pueblo de Espíritu Santo, señala Saa, «les apercibí para el viaje a la mar del sur, aunque ponían por excusa que iban los ríos muy grandes y que llovía mucho». Se trata evidentemente de una estratagema, cuyos resultados son inmediatos. El propio Saa lo relata a continuación: «con muchas razones que les dije de parte de vuestra majestad y buena maña que me di en regalarles con sal y hachuelas, que ello mucho lo estiman, y con chaquiras y agujas que les di, les convencí y quedaron apercibidos para el viaje» (Relación de Hernán González de Saa: f. 1v). La negociación prosigue a lo largo de éste y los demás viajes de Saa. En diversas ocasiones los nativos señalan «impedimentos» que obligan a Saa a modificar su ruta prevista. En otras ocasiones, el viaje solo prosigue cuando se ha producido el adecuado reparto de bienes.

Las entradas de reconocimiento son el escenario privilegiado para el intercambio de productos. En estos documentos se puede observar con más claridad el circuito de intercambio que subyace bajo la política fronteriza de Sepúlveda. Se trata de un intercambio a tres bandas, que integra no solo a las poblaciones indígenas cercanas a la frontera, sino también a parcialidades más alejadas, sin contacto directo con los emisarios del poder colonial. La clave para ello son los regalos entregados por las autoridades coloniales para cimentar las relaciones de amistad. Estos regalos consisten especialmente en herramientas de hierro (machetes, hachas, hachuelas, cuchillos, etc.), sal (muy apreciada por no existir salinas en la región) y diversos productos textiles (Relación de Hernán González de Saa: f. 6r-6v)33. Los

32 Es el caso de los indios de la provincia de Pocotavi, a los cuales no puede encontrar González de Saa en el curso de su viaje en el año 1599: «... queriéndonos partir a la dicha provincia de Pocotavi (...) nos dijeron los indios de a donde estábamos que no pasásemos adelante respecto de que todos los indios de la dicha provincia de Pocotavi habían ido a la mar con el dicho don Miguel Tulcanaza y quedaban las mujeres solas y que causaría nuestra ida mucho escándalo a las dichas indias y gente menuda...» (Relación de Hernán González de Saa: f. 3v.) También Barrett en su monografía sobre los cayapa, escrita a comienzos del siglo XX, señala la importancia de estas expediciones a la costa (Barrett, 1994: 57 y ss.).

33 En muchos casos las fuentes parecen denotar que estos productos textiles eran de fabricación criolla, siguiendo la moda europea, como es el caso evidente de las prendas con las que Sepúlveda agasaja a los caciques mulatos durante su estancia en Quito. En otros casos, sin embargo, se trata de mantas elaboradas en la región de los quijos, en el pie de monte oriental de la cordillera, que jugaban un papel importante en los intercambios rituales y el comercio al menos hasta finales del siglo XVI. Caillavet relata el ofrecimiento de una de estas mantas por parte del padre Gaspar de Torres a un cacique malaba (Caillavet, 1989: 83). 
productos eran entregados a los caciques directamente, durante sus visitas a Quito, o bien in situ a través de los representantes del poder colonial, sacerdotes mercedarios y emisarios de la Real Audiencia. En ambos casos, las connotaciones son diferentes. El gesto de entregar no significa lo mismo según quién lo entrega y según dónde se produce la entrega.

Tampoco es lo mismo para todos los actores implicados. Estos regalos son un elemento importante para comprender el éxito temporal de la estrategia diseñada por Sepúlveda para lograr la pacificación de la frontera. Sin embargo, no son una novedad absoluta en el contexto regional. Los trabajos de Chantal Caillavet señalan la existencia de un amplio marco de intercambios comerciales y rituales que durante el periodo prehispánico vincula a las poblaciones de la sierra con las poblaciones de las laderas orientales y occidentales de los Andes (Caillavet, 1989; 2000a; 2000b). Durante el siglo XVI estos contactos no se habrían interrumpido. Hasta fines de aquel siglo existen testimonios relativos a la existencia de ferias comerciales en las cuales confluyen productos de diversos sistemas ecológicos, en lugares estratégicos como Pimampiro o el poblado de Las Salinas. El mérito de Sepúlveda consiste en haber sido capaz de reconocer la importancia de estos intercambios para cimentar sobre ellos nuevas alianzas políticas, que vinculan a los poderes coloniales con las poblaciones de las tierras bajas 34 .

Por su parte, desde el lado hispano-criollo la política de asegurar fidelidades a partir de regalos remite a la imbricación entre intereses públicos (de los funcionarios imperiales) e intereses privados de individuos concretos de la elite quiteña. Como en otras partes de América, ésta es una característica central de la vida fronteriza esmeraldeña. Hernán González de Saa, citado anteriormente, es un ejemplo al respecto. Se trata de un personaje fundamental de la vida fronteriza durante los años que Sepúlveda ejerce en Quito. Saa protagoniza varias de las entradas de reconocimiento entre 1597 y 1600 . Es también la fuente financiera que contribuye a sufragar una parte importante de los costos de la nueva política. En varias ocasiones, según señala, es de su bolsillo de donde sale el dinero necesario para comprar los regalos y para equipar a los soldados que participan en las entradas 35 . A lo largo de más de una década vemos a Saa intervenir en los asuntos de la frontera, sin que sus propósitos estén del todo claros, probablemente porque sus actividades e intereses quedan más allá del campo de preocupaciones que se refleja en los documentos conservados, en su mayor parte provenientes de los funcionarios imperiales de Quito. Saa recorre constantemente la región fronteriza. En el curso de sus viajes, «arcabuz al hombro», mantiene y alimenta vínculos personales con algunos de los caciques nativos de la región. Podemos intuir su papel como intermediario cultural. Se trata de un característico personaje de frontera, que busca su fortuna en los intersticios de las relaciones interétnicas, sin dudar en arriesgar su fortuna e incluso su vida. En 1611, su muerte a manos de los indios malaba, sublevados contra la presencia española en la región del bajo río Santiago, demuestra que ésta no era una empresa sin riesgos36.

34 La manipulación de los circuitos comerciales y la generación de nuevos vínculos a partir de ello, en un contexto de contacto intercultural, ha sido señalado por Mary-Elisabeth Reeve (1984) como un elemento clave en el caso de los primeros contactos entre los misioneros jesuitas y las poblaciones de la Amazonía occidental. En este sentido, señala dentro de los procesos de redefinición de identidades étnicas, la importancia de considerar los cambios en los roles que cada grupo juega en los intercambios inducidos o intensificados por los agentes de la administración colonial.

35 Señala en este sentido: «...de mi parte he dado al padre fray Gaspar de Torres lo más del bastimento de bizcocho, pan, jamones, manteca y otras cosas desde el tiempo que ha que se empezaron las reducciones hasta ahora, y asimismo sustenté de toda comida al padre fray Jerónimo de Aguilar que así entró conmigo en el valle Vicioso, y a don Alonso Gualapiango y a los naturales de las provincias referidas les he dado mucha sal, y hachuelas, chaquiras, cuchillos, agujas, bizcocho, tasajos, botijas de vino y mucho maíz a los indios de Lita que fueron conmigo para el viaje hasta el mar». 11 de abril de 1601 (Relación de Hernán González de Saa: f. 6r-6v).

36 Información realizada por el presidente de la audiencia de Quito, Juan Fernández de Recalde, sobre la entrada realizada por Miguel Arias de Ugarte. Quito 12 de abril de 1611 (AGI, Quito: 9). 
Gran parte de la documentación conservada respecto a la política de Sepúlveda en la frontera norte se relaciona, directa o indirectamente, con el naufragio en enero del año 1600 del navío San Felipe y Santiago frente a la punta de Manglares37. La documentación relativa a este naufragio permite observar con detalle el funcionamiento de la política de control indirecto. Permite también percibir algunos de sus límites. El hundimiento, achacado a la negligencia del piloto, tiene lugar en un punto no muy alejado de la costa. Tras permanecer algunos días en la playa, los supervivientes emprenden camino hacia el sur, divididos en varios grupos. Una de las partidas, al mando del capitán Sánchez de Cuéllar, es rescatada por indígenas sometidos al jefe mulato Alonso de Illescas, quien se hace acompañar de los náufragos en su visita a Quito en el mes de junio de ese año (Relación de Alonso Sánchez de Cuellar). Enterados de la magnitud del desastre, la Real Audiencia moviliza todos los recursos a su alcance para rescatar al resto de los náufragos, a quienes se supone en manos de los indios malaba que habitan esa parte de la costa. Para ello se recurre a los caciques Luis y Alonso Gualapiango y al cacique pasto García Tulcanaza, a quienes se encomienda recorrer la región38. Los resultados, sin embargo, son magros. Apenas un español, Juan Ortega de la Torre, y seis negros esclavos son rescatados de las manos del cacique malaba Alpan, quien los tenía en su poder tras haberlos encontrado en la playa.

Los detalles de esta historia son conocidos por la declaración prestada por el propio Juan Ortega de la Torre tras su regreso a Quito. Su experiencia refleja la precariedad que tiene en la práctica, la política de control indirecto de la frontera. García Tulcanaza ejerce un poder limitado en las tierras sobre las cuales teóricamente tiene conferido poder jurisdiccional. Para obtener la libertad de los cautivos debe recurrir a estrategias que combinan la amenaza y el halago, sin poder nunca imponer su autoridad de manera directa. Su emisario, Don Rafael Guaciup esgrime ante Alpán el título de gobernador concedido por la Real Audiencia, pero además debe entregar «mantas, sombreros, sal y otras cosas»39. Son estos productos los que permiten la negociación que termina en la liberación de Ortega de la Torre y los esclavos negros que lo acompañan. Suponen, en manos de los caciques aliados, una oportunidad para reforzar su poder. El control de estos intercambios convierte a los caciques «gobernadores» en personajes clave en las redes de poder fronterizas. El intercambio controlado de productos contribuye a reforzar su posición en dos frentes: como agentes imperiales, frente a las autoridades de Quito, y como proveedores de productos de prestigio entre los grupos selváticos fuera del alcance de las autoridades quiteñas. Esto demuestra que las parcialidades indígenas, en el caso de la política de fronteras, no se limitan a jugar un papel pasivo. García Tulcanaza entrega parte de los productos obtenidos

37 Un abundante número de documentos relativos a este naufragio se conserva en: Expediente sobre la conversión de Esmeraldas, Quito, 1600 (AGl, Quito: 25). El episodio ha sido analizado por extenso en Lane (2002b: 215-225).

38 Acuerdo de la Real Audiencia de Quito para ir a buscar españoles naufragados. Quito, 2 de septiembre de 1600 (AGI, Quito: 25).

39 A la hora de relatar el rescate, llama la atención el énfasis diferente que cada actor otorga a los diferentes métodos de presión empleados. En su relación ante la Real Audiencia, García y Miguel Tulcanaza inciden sobre todo en la entrega de bienes (Relación de García y Miguel Tulcanaza ante la Audiencia de Quito. Quito, 13 de julio de 1600. [AGI, Quito: 25, f. 1r]). La referencia a la utilización del título de Gobernador, por el contrario, la encontramos en el testimonio de Ortega de la Torre (Relación de Joan Ortega de la Torre ante la Real Audiencia de Quito. Quito, 13 de julio de 1600 [AGI, Quito: 25, f. 4r]). Sin duda, estas diferencias reflejan la existencia de percepciones y narrativas diferentes respecto a la naturaleza de las relaciones entre unos grupos y otros. Desde el lado de los caciques Tulcanaza se insiste en la importancia de «agradar» a Alpan para lograr el acuerdo que haga posible la libertad de los cautivos. Por el contrario Sepúlveda, en una carta escrita al Rey poco después, señala que el rescate se obtuvo fundamentalmente «por amenazas, diciéndole que eran vasallos de Vuestra Majestad el más poderoso príncipe, Rey y señor del mundo» y solo de manera secundaria «por dádivas y buenas trazas y mañas» (Carta del oidor Juan del Barrio de Sepúlveda, a Su Majestad. Quito, 20 de octubre de 1600. [AGI, Quito: 9]). 
de los españoles a cambio de reforzar su posición como intermediario cultural40. Como Saa y Medina, Luis Gualapiango y García Tulcanaza son personajes cuya razón de ser hay que buscarla en los intersticios de libertad (y oportunidad) que genera la situación fronteriza.

Pero estas alianzas tienen también sus límites. Por un lado, ya lo hemos visto, los españoles y esclavos rescatados son muy pocos en relación con el total de náufragos supervivientes. La capacidad de los caciques aliados para intervenir en la frontera en favor de los intereses de la Real Audiencia es limitada. El entramado jerárquico construido por las políticas coloniales de reconocimiento de autoridades nativas tiene, en gran medida, un carácter fantasmático. Existe más en la voluntad de los poderes coloniales que lo crean, que en la realidad cotidiana de la vida fronteriza. Esta debilidad es evidente en ambas partes. Mientras los caciques indígenas se muestran incapaces y, en última instancia, renuncian a intervenir allí donde en teoría deben hacerlo, en Quito es muy limitado el poder de Sepúlveda para intervenir en favor de sus aliados indígenas, cuando los intereses de éstos chocan con los de otros miembros de la elite criolla o de la administración imperial. Esta incapacidad resulta evidente en el pleito que sigue a la liberación de los esclavos que se encontraban en manos de Alpán41. En él las pretensiones de los caciques Tulcanaza son apoyadas por Sepúlveda. Pero este apoyo no sirve de nada frente a la posición contraria sostenida por el capitán Sánchez de Cuéllar, que reclama la propiedad de los esclavos, y por los demás ministros de la Real Audiencia, contrarios a perder una potencial fuente de ingresos para sus siempre necesitadas arcas42.

García Tulcanaza, Luis y Alonso Gualapiango no son meros agentes imperiales. Actúan de manera autónoma y con una agenda propia. Para cumplir sus objetivos, no dudan en aprovechar las posibilidades que proporciona el sistema legal colonial, que actúa como marco legitimador de sus reclamos. La clave de su éxito consiste en ser capaces de establecer alianzas con sectores concretos de la administración colonial, que persiguiendo sus propios intereses se apoyan en ellos para hacer frente a otros sectores de la administración imperial. Para los «caciques gobernadores», la admisión del dominio colonial implica un nuevo campo de posibilidades. La premisa central consiste en saber manejar cada coyuntura, acercándose a las autoridades, multiplicando los signos de sumisión, pero manteniendo al mismo tiempo su propia autonomía como actores. A comienzos del siglo XVII, la debilidad del aparato colonial en una región tan marginal como la Audiencia de Quito y las propias urgencias personales de los funcionarios imperiales, facilitan este juego. Pero se trata de un

40 Pero García Tulcanaza no entrega todos los productos obtenidos a través de su alianza con la Real Audiencia. Se reserva para sí las herramientas de hierro, probablemente el rubro más valioso.

41 El pleito se inicia cuando Sánchez de Cuellar, capitán del navío naufragado, reclama ante la Real Audiencia la propiedad de los esclavos negros rescatados de manos de Alpán. Estos esclavos habían sido entregados por Miguel y García Tulcanaza a la Real Audiencia, cediendo sus derechos sobre ellos, a cambio de que únicamente se les reconociesen los gastos efectuados en la operación de rescate. Posteriormente, sin embargo, se muestran disconformes con el estipendio de cien pesos aprobado al efecto por la Real Audiencia, reclamando al menos quinientos pesos. Según señala su procurador, los cien pesos «no satisfacen la mitad de las costas que mis partes hicieron en ir y rescatar los dichos negros del dicho Alpán en la ropa que llevaron y caballos que alquilaron y otros gastos de su comida y aviamiento» (Petición de García y Miguel Tulcanaza ante la Audiencia de Quito. Quito, 15 de septiembre de 1600 [AGI, Quito: 25]). La disputa por los esclavos no era asunto secundario, ya que el propio Sepúlveda calculaba que su valor de mercado podía alcanzar en Quito los 3500 pesos (Carta del oidor Juan del Barrio de Sepúlveda a Su Majestad. Quito, 14 de abril de 1601 [AGI, Quito: 9]).

42 Acuerdo de la Real Audiencia de Quito sobre qué hacer con los esclavos liberados en Esmeraldas. Quito 18 de marzo de 1601 (AGI, Quito: 9). Sepúlveda insiste en su defensa de los derechos de los caciques a pesar de un segundo auto del fiscal de la Audiencia rechazando la entrega de los quinientos pesos (Respuesta del fiscal Suárez a la petición de García y Miguel Tulcanaza. Quito, 21 de octubre de 1600 [AGI, Quito: 25]). Sepúlveda señala al respecto: «los dichos caciques fueron muy quejosos y mal pagados y he tenido harto que aplacarlos y procurado darles contento» (Carta del oidor Juan del Barrio de Sepúlveda a Su Majestad. Quito, 14 de abril de 1601 [AGl, Quito: 9, f. 3v]). 
juego peligroso, con unas reglas y unos plazos definidos. La alianza entre el poder colonial y los poderes nativos dependen de la voluntad de unas pocas personas. La sociedad colonial en su conjunto no se involucra en esta política. Pese a cumplir su parte del trato, García Tulcanaza debe volver con las manos vacías.

Los límites de la política de control indirecto desarrollada por Sepúlveda son evidentes. Los arreglos alcanzados dependen de alianzas basadas en elementos extremadamente coyunturales. Nada garantiza el cumplimiento de los pactos alcanzados cuando esto implica a terceros actores. Ni la Real Audiencia reconoce el derecho de los caciques aliados a compartir los beneficios económicos de su labor de policías fronterizos, ni los caciques malabas de la frontera reconocen la autoridad de estos agentes coloniales ${ }^{43}$. Pero no se trata simplemente de actitudes personales. La política de Sepúlveda está basada en una radical asimetría, étnicamente definida, de derechos y deberes. Es también un producto de la colonialidad en tanto construcción ideológica. Se articula (y adquiere sentido) a partir de una construcción ideológica particular, de un conjunto de ideas preconcebidas respecto a los indígenas de la región esmeraldeña y a la naturaleza del territorio. De un discurso singular, que es profundamente europeo y solo en parte producto de su experiencia americana. Las grietas comienzan a aparecer desde el momento en que estas representaciones deben enfrentarse a la terca realidad de la frontera.

\section{CONCLUSIONES: LA PARTIDA DE SEPÚLVEDA Y EL ABANDONO DE LA POLÍTICA DE CONTROL INDIRECTO}

Entre 1597 y 1601 se desarrolla una coyuntura política especialmente favorable para varios de los actores implicados en la vida fronteriza. La llegada a Quito del oidor Juan del Barrio Sepúlveda supone un giro en la política de la Real Audiencia. Hasta ese momento, la escasa relevancia otorgada al tema por las autoridades coloniales se había traducido en una política de «puertas abiertas», que favorecía las empresas privadas de conquista. Sin embargo, esta estrategia había rendido pocos frutos. De ahí que desde diversos sectores de la sociedad quiteña comience a tratarse la posibilidad de controlar la región por métodos pacíficos, mediante alianzas con los caciques nativos de la zona, tanto indígenas como mulatos. Esta iniciativa, promovida por la orden de la Merced desde la década de 1570, es asumida finalmente por Juan del Bario Sepúlveda. Su labor se ve facilitada por la extraordinaria debilidad que presenta la elite criolla quiteña en los años posteriores a la frustrada revuelta de las alcabalas de 1592. Aliado a los sacerdotes mercedarios, Sepúlveda trata de construir una cadena de «gobernaciones» indígenas, dirigidas por caciques de la región del piedemonte andino, quienes debían garantizar la seguridad de las poblaciones serranas frente a posibles ataques de las tribus hostiles de las tierras bajas. En la costa, los cacicazgos mulatos debían cumplir una función análoga frente a eventuales ataques de potencias extranjeras. En paralelo a ello, también el mundo indígena de la frontera está cambiando. Surgen nuevos patrones de ocupación del espacio, con poblaciones de mayor tamaño en sustitución del hábitat disperso tradicional y una jerarquización incipiente. Se trata de un escenario fluido, en el cual se construyen nuevas identidades y se reinterpretan otras, siendo posible encontrar poblaciones mixtas y un entramado muy complejo de relaciones interétnicas.

43 A este respecto resulta muy explícito el relato de Ortega de la Torre. Pese a los acuerdos alcanzados, su regreso acompañado de Don Rafael, el emisario de García Tulcanaza, se realiza «viniendo por el camino nos salieron a matar a mí y a ellos tres veces y fue dios servido de guardarnos viniendo rompiendo monte y no camino derecho». Lo cual evidencia un control muy precario de la frontera. Relación de Joan Ortega de la Torre ante la Real Audiencia de Quito. Quito, 13 de julio de 1600 (AGI, Quito: 25, f. 4r). 
En octubre de 1600, en la cúspide de su éxito, Sepúlveda se enorgullece en una carta enviada al Rey de su labor como pacificador de la frontera esmeraldeña ${ }^{44}$. No solo la región se encontraba ahora protegida frente a cualquier amenaza externa, si no que además esto se había conseguido sin ningún gasto para la Corona. Los costos de la empresa, según señalaba Sepúlveda, habían corrido por cuenta de los caciques de la región. La Real Audiencia se había limitado a reconocer su poder, a asistirlos ocasionalmente con algunos soldados y a dotarlos de títulos que reconocieran una autoridad que de hecho ya ejercían sobre las poblaciones de la región. Planteada así la situación parecía idílica: un final feliz para casi cien años de frustraciones, derrotas y muertes. La realidad, sin embargo, iba por otro camino. Ese mismo año, el naufragio del San Felipe había demostrado que no todos los grupos ribereños se encontraban pacificados. Pese a haber alcanzado con vida la costa, muchos de los náufragos habían desaparecido en manos de grupos hostiles. Aunque la intervención de Alonso Illescas y de García Tulcanaza había permitido el rescate de algunos de los desafortunados tripulantes, estas muertes demostraban que la región no se hallaba por completo sometida al control de las autoridades de Quito.

La política de Sepúlveda tampoco había puesto fin a las guerras interétnicas. En 1605 un grupo de mulatos apoyados por «indios de guerra de Esmeraldas» y «dos arcabuceros españoles» asaltan un poblado de indios yumbos cercano a Canzacoto. En 1607 se repite la situación. El objetivo ahora es el pueblo de Nimbo, donde ante la reiteración de los ataques se habían agrupado los indios de la encomienda otorgada a Pedro de Arévalo. En ambas ocasiones la respuesta de las autoridades oscila entre la negociación y la represión. Las partidas de castigo formadas en Quito no llegan a entablar combate con los caciques mulatos, quienes nuevamente demuestran su funcionalidad como guardianes de la costa en marzo de 1606, al prestar socorro a los tripulantes del Nuestra Señora de la Concepción, que ante la falta de alimentos habían desembarcado en aquellas playas45.

Las cartas de Sepúlveda una y otra vez inciden en su deseo de abandonar Quito. «No debe haber tres en todas vuestras reales audiencias —señala- que sean más antiguos que yo»46. En 1602 sus anhelos se ven recompensados, cuando por medio de una real provisión se determina su traslado a Lima para continuar la visita comenzada por el fallecido Alonso Fernández de Bonilla, arzobispo de México ${ }^{47}$. La partida de Sepúlveda hace estallar el entramado de alianzas coyunturales levantado en la frontera. La Real Audiencia abandona la política de control indirecto, considerada excesivamente cara e improductiva. A comienzos del siglo XVII no existe dentro de la administración colonial un fondo específicamente destinado a estos fines. Para sufragar los gastos, Sepúlveda debe acudir a diversas fuentes, entre las que destaca la cesión de los tributos vacos resultado de la muerte de Catalina de Valer, aprobada por el virrey Luis de Velasco en septiembre del año 160048. Sepúlveda señala también haber dedicado al empeño parte de su propia hacienda49. Otros habitantes

${ }^{44}$ Carta del oidor Juan del Barrio de Sepúlveda a Su Majestad. Quito, 15 de octubre de 1600 (AGI, Quito: 9).

45 El relato de estos sucesos en Archivo del Duque del Infantado (Madrid), Papeles de Montesclaros (libro 15, expedientes 6-7) (In: Salomon, 1997: 57 y ss).

46 Carta del oidor Juan del Barrio de Sepúlveda a Su Majestad. Quito, 15 de abril de 1600 (AGl, Quito: 9). En esta misma carta, Sepúlveda atribuye su postergación al hecho de no contar con protectores poderosos en la corte. En abril de 1600 señala: «no sé la causa más que mi desventura y no haber tenido hombre que favoreciese mis buenos, ordinarios y extraordinarios, y leales servicios». Carta del oidor Juan del Barrio de Sepúlveda a Su Majestad. Quito, 14 de abril de 1601 (AGl, Quito: 9).

47 Carta del oidor Juan del Barrio de Sepúlveda a Su Majestad. Guayaquil, 25 de abril de 1602 (AGl, Quito: 9). La real cédula con el nombramiento de Sepúlveda es de 9 de abril de 1601. El 4 de noviembre es recibida en Lima y el 27 de noviembre en Quito. La partida de Sepúlveda tiene lugar el 19 de marzo de 1602.

48 Carta del virrey del Perú, Luis de Velasco, al oidor de la Audiencia de Quito Juan del Barrio de Sepúlveda. Lima, 18 de septiembre 1600 (AGl, Quito: 25).

${ }^{49}$ Carta de oidor Juan del Barrio de Sepúlveda a Su Majestad. Quito, 15 de octubre de 1600 (AGl, Quito: 9). 
de Quito, por diversas razones, también colaboran en los esfuerzos mediante donativos en metálico o financiando directamente los costos de las expediciones ${ }^{50}$. Pero la política fronteriza no cuenta con una fuente de financiamiento estable.

Un documento de 1602 elaborado por los oficiales a cargo de la Caja Real señala que ese año se habían destinado casi dos mil pesos para la «reducción de los mulatos e indios de las Esmeraldas y provincias de cayapa»51. En sus cartas al Rey, Sepúlveda insiste en el ahorro que se sigue comparando estos gastos con el millón de pesos perdido en el naufragio del San Felipe (Carta del oidor Juan del Barrio de Sepúlveda a Su Majestad. Quito, 14 de abril de 1601 [AGl, Quito : 9]). En otra ocasión, señala también la diferencia entre lo gastado a través de su política de control indirecto, que descarga parte del esfuerzo financiero en los caciques indígenas, y el costo potencial de seguir la estrategia de entradas violentas, que calcula en más de 30000 pesos (Carta del oidor Juan del Barrio de Sepúlveda a Su Majestad. Quito, 15 de octubre de 1601 [AGI, Quito : 9]). Pero éste no es un tema sobre el que exista consenso en Quito. Desde muy pronto, ni siquiera existe unanimidad entre los ministros de la Real Audiencia, a quienes Sepúlveda acusa de no haber puesto en el empeño «ni un jarro de agua» (Carta del oidor Juan del Barrio de Sepúlveda a Su Majestad. Quito, 15 de octubre de 1601 [AGI, Quito : 9]).

La financiación de la política de fronteras es el punto de quiebre más evidente entre Sepúlveda y los grupos de elite de la Real Audiencia. Sin embargo, este desacuerdo solo es el síntoma de un descontento más profundo. Durante los primeros veinte años del siglo XVII la frontera esmeraldeña es el escenario hacia el cual se proyectan una serie de proyectos enfocados a reconducir la economía de la colonia quiteña. Con el aumento de la producción de textiles, la apertura de un nuevo camino entre Quito y el océano Pacífico pasa a ser considerada como el elemento indispensable para el desarrollo regional (Rueda Novoa, 1992). Es evidente que la política de Sepúlveda, que privilegiaba el control indirecto de la región y su conversión en un territorio de misión controlado por la orden de la Merced, no podía resultar del agrado de las élites quiteñas.

¿Quiere esto decir que la actuación de Sepúlveda constituye un episodio aislado, sin trascendencia para la historia posterior de la frontera esmeraldeña? En parte sí, pero no del todo. La estrategia diseñada por el oidor cordobés es tanto un producto personal como el síntoma de un conjunto de cambios que por entonces se vienen produciendo, no solo en Quito, sino en el conjunto del imperio español de América. Cambios de actitudes, cambios en cuanto a prácticas administrativas y cambios en cuanto a percepciones. La labor de Sepúlveda constituye el primer ejemplo de un decidido intervencionismo de las autoridades imperiales en la política fronteriza. Con mayor intensidad, el ejemplo va a ser seguido en las décadas posteriores por los presidentes destinados a Quito, Miguel de Ibarra, Juan Fernández de Recalde y, sobre todo, Antonio de Morga (Hernández Asensio, 2004).

50 En 1600 Rodrigo Calderón Manrique de Lara y su esposa Tomasina Figueroa habían renunciado a sus derechos sobre los tributos vacos de Catalina de Valer, para que éstos fueran destinados a financiar la política fronteriza. Adicionalmente habían donado cien pesos para este efecto (Auto de Juan del Barrio de Sepúlveda, oidor de la Audiencia de Quito, sobre financiamiento de la conversión de las Esmeraldas. Quito, 10 de octubre de 1600. [AGI, Quito: 25]). Sin embargo, ese mismo año había fracasado la iniciativa de Sepúlveda de levantar un donativo general entre los habitantes de la ciudad, encargado al regidor Pedro Ponce Castillejo (Petición de Juan del Barrio de Sepúlveda, oidor de Quito, al Rey y relación sobre el estado de la conversión de Esmeraldas. Quito, 19 de julio de 1600 [AGI, Quito: 9]). En vista de ello Sepúlveda, con acuerdo de los contadores reales, había decidido aplicar para este efecto el resultante de la venta de los esclavos rescatados por García Tulcanaza.

51 Carta de los oficiales reales de Quito, Francisco de Cáceres y Gaspar Alonso de Zúñiga, a Su Majestad. Quito, 13 de abril de 1600 (AGl, Quito: 19). En concreto lo gastado son «dos mil setecientos noventa y ocho pesos de buen oro de ley de veintidós quilates». La cantidad es significativa aunque muy inferior a los 31000 pesos de plata destinados ese mismo año al levantamiento y traslado desde Guayaquil de tropas con destino a las guerras fronterizas en el reino de Chile. 
En una perspectiva más amplia, el giro de la política fronteriza protagonizado por Sepúlveda se enraíza y adquiere sentido dentro de un cambio de sensibilidad más amplio, que trasciende con mucho su propia labor. Un cambio estratégico general, que empieza a intuirse en estos años, en cuanto al modelo de colonización española de América, que cada vez más tiende a privilegiar el fortalecimiento de los espacios andinos centrales y en perjuicio del abandono (o control indirecto) de los espacios marginales. Está emergiendo aquí una nueva forma de mirar la selva y sus habitantes. Un nuevo estilo, condicionado ideológica y religiosamente, que encontramos recogido en el texto de Gaspar de Torres y que, a través del periodo colonial, se va a prologar hasta nuestros días.

\section{Referencias citadas}

\section{Fuentes primarias}

AGI - Archivo General de Indias

Audiencia de Quito: leg. 8, 9, 25, 211

Lima: leg. 1

Indiferente General: leg. 2093

ANH - Archivo Nacional de Historia

Quito, sección Real Hacienda: caja 36

\section{Fuentes secundarias}

ALCINA FRANCH, J., 2001 - Introducción. In: Descripción de la provincia de las Esmeraldas (M. Cabello Balboa); Madrid: Consejo Superior de Investigaciones Científicas.

BARRET, S. A., 1994 - Los indios cayapas del Ecuador, 407 p.; Quito: Abya Yala.

BURGOS, H., 1995 - Primeras doctrinas en la Real Audiencia de Quito, 1570-1640, 488 p.; Quito: Abya Yala.

CABELLO BALBOA, M., 2001 [1583] -Descripción de la provincia de las Esmeraldas, 136 p.; Madrid: Consejo Superior de Investigaciones Científicas. Edición, introducción y notas de José Alcina Franch.

CAILLAVET, C., 1989 - Entre sierra y selva: las relaciones fronterizas y sus representaciones para las etnias de los Andes septentrionales. Anuario de Estudios Americanos, 46: 71-91; Sevilla.

CAILLAVET, C., 1996 - Antropofagia y Frontera: el caso de los andes septentrionales. In: Frontera y poblamiento: estudios de historia y antropología de Colombia y Ecuador (Chantal Caillavet \& Ximena Pachón, eds.): 57-109; Santafé de Bogotá: Instituto Francés de Estudios Andinos, Instituto de Investigaciones. 
CAILLAVET, C., 2000a - La sal de Otavalo. Continuidades indígenas y rupturas coloniales. In: Etnias del norte: etnohistoria e historia de Ecuador (Chantal Caillavet): 59-83; Quito: Casa de Velásquez, Instituto Francés de Estudios Andinos, Abya Yala.

CAILLAVET, C., 2000b - Territorio y ecología del grupo prehispánico otavalo. In: Etnias del norte: etnohistoria e historia de Ecuador (Chantal Caillavet): 43-57; Quito: Casa de Velásquez, Instituto Francés de Estudios Andinos, Abya Yala.

CUMMINS, T., 1999 - Retrato de los Mulatos de Esmeraldas: don Francisco de la Robe y sus hijos Pedro y Domingo. In: Los siglos de oro en los virreinatos de América (1550-1700): 170-172; Madrid: Sociedad Estatal para la Conmemoración de los Centenarios de Felipe II y Carlos V.

CUMMINS, T. \& TAYLOR, W., 1998 - The Mulatto Gentlemen of Esmeraldas, Ecuador. In: Colonial Spanish America: A Documentary History (K. Mills \& W. Taylor, eds.): 147-149; Wilmington: Scholarly Resources.

DE BOER, W., 1994 - Returning to Pueblo Viejo: History and Archeology of the Chachi (Ecuador). In: Archaeology in the Lowland American Tropics: Current Analytical Methods and Applications (Peter W. Stahl, ed.); New York: Cambridge University Press.

GONZÁlEZ, J., 1949 - Documentos para la historia de la Audiencia de Quito; Madrid: Afrodisio Aguado.

HERNÁNDEZ ASENSIO, R., 2004 - La frontera occidental de la audiencia de Quito: viajeros y relatos de viajes (1595-1630), 214 p.; Lima: Instituto de Estudios Peruanos, Instituto Francés de Estudios Andinos.

HERNÁNDEZ ASENSIO, R., 2006 - Poblaciones afro descendientes en la costa ecuatoriana durante el siglo diecisiete. Una experiencia histórica subalterna entre la autonomía y la mediación cultural. Balance historiográfico. Seminario Internacional sobre Estudios Africanos en América Latina. Herencia, Presencia y Visiones del Otro. Bahía, 4 y 5 de septiembre.

LANDÁZURI, C., 1995 - Los curacazgos pastos prehispánicos: agricultura y comercio, siglo XVI, 229 p.; Quito: Banco Central del Ecuador.

LANE, K., 2002a - Captivity and Redemption: Aspects of Slave Life in Early Colonial Quito and Popayán. The Americas, 57: 225-246.

LANE, K., 2002b - Quito 1599. City and Colony in Transition, 288 p.; Albuquerque: University of New Mexico Press.

MARTÍN DE CARRANZA, B. (atribuido), 1995 [1569] - Relación de las provincias de Esmeraldas que fue a pacificar el capitán Andrés Contero. In: Relaciones Histórico Geográficas de la Audiencia de Quito, vol. 1 (Pilar Ponce Leiva, ed.); Madrid: Consejo Superior de Investigaciones Científicas.

MONROY, J., 1935 - Los religiosos de la Merced en la costa del Antiguo Reino de Quito, 2 vols.; Quito: Labor.

OFFEN, K. , 2002 - The Sambo and Tawira Miskitu: The Colonial Origins and Geography of Intra-Miskitu Differentiation in Eastern Nicaragua and Honduras. Ethnohistory, 49(2): 319-373.

PALOP MARTÍNEZ, J., 1994 - Mapa étnico del sur de Colombia y norte del Ecuador durante los siglos XVI y XVII. Revista Española de Antropología Americana, 24: 139-153.

PALOP MARTÍNEZ, J., 1995 - Asentamientos de indios y mulatos en la provincia de Esmeraldas durante el siglo XVII. In: Primer encuentro de investigadores de la costa ecuatoriana en Europa: arqueología, etnohistoria, antropología sociocultural; Quito: Abya Yala. 
POWELL, P. W., 1944 - Spanish Warfare against the Chichimecas in 1570's. Hispanic American Historical Review, 24: 580-604.

RAMÓN, G., 1990 - El poder y los norandinos: la historia en las sociedades norandinas del siglo XVI, 157 p.; Quito: Centro Andino de Acción Popular.

REEVE, M-E., 1984 - Regional Interaction in the Western Amazon: The Early Colonial Encounter and the Jesuit Years: 1538-1767. Ethnohistory, 41: 106-138.

RUEDA NOVOA, R., 1988 - La ruta a la Mar del Sur: un proyecto de las elites serranas en Esmeraldas (siglo XVIII). Procesos: revista ecuatoriana de Historia, 3: 33-53.

RUEDA NOVOA, R., 2001 - Zambaje y autonomía: historia de la gente negra de la provincia de Esmeraldas, 195 p.; Esmeraldas: Municipalidad.

RUEDA NOVOA, R., 2005 - La crónica de Miguel Cabello Balboa: evangelización y reducción de los negros de Esmeraldas y el proyecto económico de la Real Audiencia de Quito. Siglos XVI-XVII. In: Passeurs, mediadores culturales y agentes de la primera globalización en el Mundo Ibérico, siglos XVI-XIX (Scarlett O'Phelan Godoy \& Carlos Salazar-Soler, eds.): 55-88; Lima: Pontificia Universidad Católica del Perú, Instituto Riva-Agüero, Instituto Francés de Estudios Andinos.

SALOMON, F., 1980 - Los señores étnicos de Quito en la época de los incas, 370 p.; Otavalo: Instituto Otavaleño de Antropología.

SALOMON, F., 1997 - Los yumbos, niguas y tástchila o colorados durante la colonia española: etnohistoria del noroccidente de Pichincha, Ecuador, 131 p.; Quito: Abya-Yala.

SAVILLE, M. H., 1907 - The Antiquities of Manabí, Ecuador: A Preliminary Report. Contributions to South American Archaeology; New York: Museum of the American Indian.

SAVILLE, M. H., 1910 - The Antiquities of Manabí, Ecuador: Final Report. Contributions to South American Archaeology; New York, Museum of the American Indian.

SAVOIA, R., 1988 - El negro Alonso de Illescas y sus descendientes (entre 1553 y 1867). In: Actas del Primer Congreso de Historia del Negro en el Ecuador y el sur de Colombia (Rafael Savoia, ed.): 29-62; Esmeraldas: Abya Yala, Centro Cultural Afroecuatoriano.

SZÁSZDI, A., 1986 - El Trasfondo de un cuadro: 'Los Mulatos de Esmeraldas' de Andrés Sánchez Galque. Cuadernos Prehispánicos, 12: 93-142.

TAYLOR, A-C., 1994 - Una categoría irreductible en el conjunto de las naciones indígenas: los jíbaro en las representaciones occidentales. In: Imágenes e imagineros: representaciones de los indígenas ecuatorianos, siglos XIX y XX (Blanca Muratorio, ed.): 75-107; Quito: Facultad Latinoamericana de Ciencias Sociales.

WEBER, D., 1990 - The Spanish Frontier in North America; New Haven: Yale University Press. 